\title{
THE DETERMINANTS OF THE ADOPTION OF CURRENT RECOMMENDED PRACTICES FOR NATURAL RESOURCE MANAGEMENT IN THE WIMMERA REGION OF AUSTRALIA
}

\author{
JOHN HICKS, PARIKSHIT BASU, ALLAN CURTIS \& EMILY MENDHAM \\ Institute of Land, Water and Society, Charles Sturt University, Australia
}

\begin{abstract}
The Wimmera Catchment Management Authority (WCMA) is responsible for approximately 30,000 square kilometres of land in the west of the state of Victoria in Australia. The predominant land use in the Wimmera is agriculture which is primarily responsible for the clearing of 85 percent of the region's native vegetation. The 2003-2008 Wimmera Regional Catchment Strategy (WRCS) confirmed the natural resource management (NRM) priorities for the Wimmera Region. The Strategy document identified a number of current recommended practices (CRP), the adoption of which would contribute to the future sustainability of the region. Qualitative research identified thirteen critical CRPs that were investigated in a survey of land-management practices in the Wimmera. The research reported in this paper is based on the data collected in this survey of 1003 of the region's landholders. Our research identifies the main determinants of the number of CRPs taken up by the region's landholders as the size of landholding, direct government support and conservation education.

Keywords: natural resource management, current recommended practices, farmers, Australia.
\end{abstract}

\section{INTRODUCTION}

The Wimmera Catchment Management Authority (WCMA) is responsible for approximately 30,000 square kilometres of land in the west of the state of Victoria in Australia. The predominant land use in the Wimmera is agriculture which is primarily responsible for the clearing of 85 percent of the region's native vegetation. The 2003-2008 Wimmera Regional Catchment Strategy (WRCS) confirmed the natural resource management (NRM) priorities for the Wimmera Region. The Strategy document identified a number of current recommended practices (CRP), the adoption of which would contribute to the future sustainability of the region. Qualitative research identified thirteen critical CRPs that were investigated in a survey of land-management practices in the Wimmera. The research reported in this paper is based on the data collected in this survey of 1003 of the region's landholders. Our research seeks to identify the determinants of the number of CRPs taken up by the region's landholders and to provide policy recommendations for enhancing the future adoption of NRM activities in the region. The next section considers the theoretical model on which the analysis is based. Section 3 describes the data and how it is utilised in the context of the stated model. In section 4 we introduce the econometric procedures used to analyse the data, present and discuss the results. Section 5 concludes providing an analysis of the implications of our findings.

\section{MODEL}

Pannell et al. [1] and Curtis and Mendham [2] identified a number of sets of factors (or elements) that impact on the adoption of conservation practices by landholders. For our purposes, we have categorised them into the following four categories: 
1. The nature or characteristic of the practice $(\mathrm{P})$ being considered. A practice is more likely to be adopted if there are net benefits from its adoption (relative advantage) and the more easily the practice can be implemented (trialability). Pannell et al. [1] argued that "... relative advantage is the decisive factor determining the ultimate level of adoption of most innovations in the long run".

2. The characteristics of the landholder (and the landholder's family) (L) and their family circumstances. "Depending on their personal and family circumstances, the issues about which landholders are most concerned at a particular time may not relate to conservation, or any aspect of land management" [1].

3. The prevailing social context (S). Landowners are able to source information about conservation from a wide range of providers. However, it is argued that the impact of this information will largely be determined by the social context in which it is received. For example, do they trust their extension agent? As Pannell et al. [1] have stated, "Adviser credibility and trust is a valuable commodity".

4. The nature of any (government) intervention (G). Clearly the policies of all levels of government can impact on the relative advantage of adopting conservation practices [1].

Curtis and Mendham [2] previously explored the determinants of individual CRPs in the Wimmera Catchment Area. Our goal, in this research, was to endeavour to identify those factors that are important in determining the number of Current Recommended Practices (NCRP) taken up. Thus, we hypothesise that:

$$
N C R P=f(P, L, S, G)
$$

\section{DATA}

The data in this analysis is based on a survey of 1003 landholders commissioned by the Wimmera Catchment Management Authority (WCMA) and originally reported, in detail, in Curtis and Mendham [2]. The survey was conducted in the WCMA region during 2011 and achieved a response rate of 49 percent (494 completed surveys retuned). Curtis and Mendham [2] tested for non-respondent bias against selected data from the Wimmera in the ABS Australian Farm Census and concluded that there was no significant bias. Amongst the research objectives of the survey was the objective to "provide a coherent explanation of landholder adoption of recommended practices identified in the WCMA Regional Catchment Strategy".

Topics included items that can be directly related to the classification of factors from Pannell et al. [1] discussed above. The principal survey topics are reported in Curtis and Mendham [2] as:

- $\quad$ long-term plans for the property;

- $\quad$ issues of concern at property and district scales;

- beliefs and attitudes about roles and responsibilities of different NRM actors;

- $\quad$ attitudes about the management of wetlands and groundwater;

- trust in the WCMA

- $\quad$ values attached to the property and held values;

- knowledge of NRM processes and practices

- confidence in recommended practices for improvement in resource condition;

- $\quad$ sources of information about NRM; 
- $\quad$ land use and enterprise mix;

- implementation of CRP for sustainable agriculture and biodiversity conservation;

- involvement in NRM programs; and

- background social and farming topics (e.g. occupation, place of residence, property size, on and off-property work and income, membership of Landcare and commodity groups).

The survey focused on 13 Current Recommended Practices (CRP). As explained by Curtis and Mendham [2], "some items were cropping or grazing specific, while others applied to all or most landholders. Some items referred to the total time of property management while others asked about actions in the last five years of property ownership".

\subsection{Dependent variable}

Following Curtis and Mendham [2] we restrict our analysis to 11 of the 13 Current Recommended Practices. NCRP is therefore, the total number of practices that each landholder has engaged in over the past five years. The practices utilised are:

1. An area of trees and shrubs planted (including direct seeding).

2. An area of farm forestry established.

3. Fencing erected to manage stock access to waterways (rivers/streams/wetlands).

4. An area of native bush /grasslands fenced to manage stock access.

5. An area of perennial pasture and lucerne sown.

6. Off-stream watering points established.

7. An area of gully erosion addressed.

8. The use of adaptive no-till techniques on part of the sown area.

9. The use of minimum tillage techniques on part of the sown area

10. Precision farming techniques for cropping used.

11. The creation of an artificial wetland.

Items omitted because they were not applicable to the majority of the farms in the survey were "monitoring bore height" and "monitoring bore water quality".

\subsection{Independent variables}

Curtis and Mendham [2] provide a list of variables where there was a significant relationship to at least one CRP. Because there were a large number of variables resulting from the survey, we used this list to identify the variables that were most likely to prove fruitful in the conduct of our regression experiments. Some of the independent variables are variables that management agencies can seek to influence. Others are those over which their influence would be problematic - although they should be aware of them.

3.2.1 The nature or characteristic of the practice $(\mathrm{P})$ being considered

In considering variables under this element we are focussed on the relative advantage of the adoption of conservation practices. The survey gave a number of structured responses to the question 'Why your property is important to you?' and asked respondents to assess, on a scale of 1-6, the importance they attributed to each response. The responses were divided between responses that indicated that the property was important for environmental reasons, economic reasons and social reasons. The data allowed the construction of single indices, or constructs, each with a Cronbach Alpha in excess of 0.7, to act as an index of the 
economic value of the property to the landholder (ECONINDEX), the environmental value of the property to the landholder (ENVIRONINDEX) and the social value of the property to the landholder (SOCIALINDEX). It was expected that the number of conservation practices adopted by a landholder would be positively related to ENVIRONINDEX and negatively related to ECONINDEX.

\subsubsection{The characteristics of the landholder (L)}

The survey was conducted amongst landholders, and not all landholders are farmers. Therefore, to account for the fact farming landholders may respond differently to environmental issues than non-farming landholders we introduced the variable FARMER which takes the value 1 when the landholder is a farmer and 0 otherwise.

One would expect that the larger the property managed by a landholder, the greater the opportunity to implement CRPs. LAND is a variable providing the amount of land owned/managed by each respondent and was expected to be positively related to NCRP. Increasingly environmental economists are using attitudinal constructs to explain the propensity to undertake conservation actions (see for example Ojea and Loureiro [3]). The survey asked respondents to identify on a scale the level of importance they attributed to a range of values. From the responses it was possible to construct indices for the importance of biospheric attitudes (BIOSPHERIC), altruistic attitudes (ALTRUISTIC) and egoistic attitudes (EGOISTIC). We expected NCRP to be positively related to the first two and negatively related to the third.

The more a landholder knows about conservation practices, how they are implemented and the impact they will have - both on the environment and on farm income - the better positioned the landholder is to make decisions about their implementation. The survey sought a self assessment from respondents on the level of knowledge (on a scale from no knowledge to very sound knowledge) on a number of topics related to conservation practices. The results of this exercise were used to create an index of knowledge of conservation practices (KNOWLEDGE). We expected that higher levels of knowledge would be associated with a larger number of CRPs being implemented.

Berrone et al. [4] have argued that family firms (and by extension family farms) symbolize the family's heritage and tradition and is a long-term family investment to be bequeathed to descendents. Thus, not only are planning horizons longer but also the goals tend to be wider than just economic. This suggests that succession planning may be positively associated with the adoption of conservation measures. We tested for this by employing the variable SUCCESSION which was given a value of 1 where a respondent had indicated that there was a relative interested in taking over from the current landholder and 0 otherwise. As indicated above, we expected SUCCESSION to be positively associated with NCRP.

A basic tenet of business operations is that well planned businesses tend to run more efficiently. The same principle should hold when implementing conservation measures. Thus, we argue that where a landholder has a property management plan there was likely to be a greater adoption of CRPs. To test this, we introduced the variable PLAN which was given the value of 1 when a property management plan was in place and 0 otherwise.

It is likely that land use will determine the number of CRPs that are adopted by an individual landholder. To test for this, we employed a dummy variable for cropping (CROP) which took the value of 1 when the land was used to grow wheat and 0 otherwise. 


\subsubsection{The prevailing social context (S)}

The first variable used in this group captures the extent to which landholders were aware of the problem of salinity (SALT) impacting on their property on a scale of $1-5$. We hypothesised that the more they regarded the issue as a problem, the more likely they would be to do something about it.

A number of questions sought information on the flow of information within the context of the Wimmera community. The variable COURSE provided responses $(1=$ yes, $0=$ no $)$ to the question "In the past 5 years have you completed a short course relevant to property management?" We expected those who answered yes to be more likely to introduce CRPs. Similarly, we expected a positive relationship between the number of CRPs adopted and each of membership of a landcare group (LANDCARE) and membership of a local commodity group (COMMODITY). On the assumption that the more information groups a landholder was a member of the greater the flow of information they are exposed to, we aggregated responses to the last three variables to provide the variable (INFORMATION).

\subsubsection{The nature of any (government) intervention $(\mathrm{G})$}

The last variable is GOVERNMENT. GOVERNMENT recorded the response (yes $=1$, no $=0$ ) to the question "In the past 5 years, did federal or state government programs or the Wimmera Catchment Management Authority support work on your property?"

\section{STATISTICAL PROCEDURES AND RESULTS}

For each respondent, our dependent variable (NCRP) will take a value between 0 and 11 . Wooldridge [5] argues that under such circumstances a Poisson regression model may be more appropriate than a linear regression model estimated with ordinary least squares (OLS). We began, however, with the later in Table 1 and report the outcome to the former in Table 2 . In both cases we have only retained in the tables those explanatory variables, the coefficients of which have proved significant.

Notwithstanding a number of experiments, the following variables could not be found to have a significant impact on the number of CRPs adopted: ECONINDEX, ENVIRONINDEX, SOCIALINDEX, FARM, ALTRUISTIC, EGOISTIC, SUCCESSION, SALT, LANDCARE, COMMODITY and INFORMATION. In the Poisson regressions the coefficient for PLAN was also insignificant.

As can be seen from the tables, the variables that proved to have a significant impact on NCRPs adopted are LAND, BIOSPHERIC, KNOWLEDGE, CROP and GOVERNMENT.

Table 1: OLS results. Dependent variable: NCRP.

\begin{tabular}{lccc}
\hline & Coefficient & Standard error & t-statistic \\
\hline LAND & 0.002552 & 0.0000632 & 4.04 \\
BIOSPHERIC & 0.2429258 & 0.0865824 & 2.81 \\
KNOWLEDGE & 0.7510592 & 0.118118 & 6.26 \\
PLAN & 0.4146907 & 0.1666036 & 2.49 \\
CROP & 1.011607 & 0.1654944 & 6.11 \\
GOVERNMENT & 0.7565662 & 0.0690126 & 10.96 \\
CONSTANT & -1.776256 & 0.5164597 & -3.44 \\
\hline Observations & 409 & & \\
R-Squared & 0.4824 & & \\
\hline
\end{tabular}


Table 2: Poisson results. Dependent variable: NCRP.

\begin{tabular}{lccc}
\hline & Coefficient & Standard error & Z-statistic \\
\hline LAND & 0.000072 & 0.00019 & 3.78 \\
BIOSPHERIC & 0.778422 & 0.033502 & 2.32 \\
KNOWLEDGE & 0.2950488 & 0.04435 & 6.62 \\
CROP & 0.388269 & 0.0671492 & 5.78 \\
GOVERNMENT & 0.1875717 & 0.0208425 & 9.00 \\
CONSTANT & -0.6427828 & 0.2110707 & -3.05 \\
\hline Observations & 409 & & \\
Pseudo R-Squared & 0.1385 & & \\
\hline
\end{tabular}

\section{CONCLUSIONS}

The results suggest that the model adopted is an appropriate tool for analysing the determinants of the number of CRPs adopted by farmers in the Wimmera. However, a number of the influences that were expected to be influential were in fact not. This finding is consistent with the findings of Curtis and Mendham [2] who found that none of the dependent variables had a significant impact on each individual CRP - although each of those in this research did have a significant impact on at least one of the CRPs in that study.

In terms of application, it appears that if policy makers wish to influence the number of CRPs taken up by landholders across the Wimmera (rather than enhancing the adoption of a particular policy) they should focus their energy on the larger farms in cropping areas. The increased provision of direct government support to landholders will certainly raise the number of CRPs adopted. However, so too will policies that enhance the knowledge of landholders about conservation practices. Perhaps a more difficult task will be bringing about a greater acceptance of biospheric values. However, success in this task is likely to bring reward in a larger take-up of CRPs.

\section{REFERENCES}

[1] Pannell, D.J., Marshall, G.R., Barr, N., Curtis, A., Vanclay, F. \& Wilkinson, R., Understanding and promoting the adoption of conservation technologies by rural landholders. Journal of Experimental Agriculture, 46, pp. 1407-1424, 2006.

[2] Curtis, A. \& Mendham, E., The Social Drivers of Natural Resource Management in the Wimmera Region: Final report to the Wimmera Catchment Management Authority, Wimmera Catchment Management Authority, 2012.

[3] Ojea, E. \& Loureiro, M., Altruistic, egoistic and biospheric values in willingness to pay (WTP) for wildlife. Ecological Economics, 63, pp. 807-814, 2007.

[4] Beronne, P., Cruz, C. \& Gomez-Mejia, L.R., Socioemotional wealth in family firms: theoretical dimensions, assessment approaches and agenda for future research. Family Business Review, 25(3), pp. 258-279, 2012.

[5] Wooldridge, J. M., Introductory Econometrics, Thomson: Australia, 2006. 